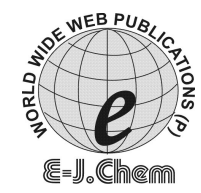

http://www.e-journals.net

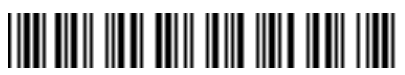

ISSN: 0973-4945; CODEN ECJHAO

E-Journal of Chemistry

Vol. 4, No. 4, pp. 550-558, October 2007

\title{
Study of the $\beta$-Cyclodextrin Imipramine Hydrochloride Inclusion Complex and Determination of its Stability Constant (K) by UV-Visible Spectroscopy
}

\author{
ALAMDAR ASHNAGAR ${ }^{*}$ NAHID GHARIB NASERI ${ }^{\#}$, and BITA KHANAKI \\ * School of Pharmacy, Ahwaz Jundi Shapour Univ. of Medical Sciences, \\ Ahwaz, Iran. Tel. No. (0098 611-3342197) \\ \#Ahwaz Faculty of Petroleum Engineering, Petroleum Univ. of Technology, \\ Abadan Road, Ahwaz, Iran. \\ ngharibnaseri@yahoo.com; aashnagar2003@yahoo.com
}

Received 14 March 2007; Accepted 25 May 2007

\begin{abstract}
In this research, the interactions of imipramine hydrochloride drug with $\beta$ - cyclodextrin and the stability constant $(\mathrm{K})$ of the inclusion complex formed between them were investigated by using UV-visible spectroscopy. Solutions consisting of a known and constant amount of imipramine hydrochloride and varying amounts of $\beta$ - cyclodextrin were prepared in $0.1 \mathrm{M}$ phosphate buffer $(\mathrm{pH}$ 7.4). The final solutions had cyclodextrin concentrations between 0.0011 and $0.0153 \mathrm{M}$. UV-visible spectra of each solution was taken at $\lambda_{\max }=250 \mathrm{~nm}$. The absorbances at this wavelength were recorded and plotted against cyclodextrin concentrations. From the graph, the concentrations of free and bound imipramine hydrochloride and free $\beta$-cyclodextrin were calculated using the Beer-Lambert law. From these data, the stability constant was calculated and a value of $\mathrm{K}=52.26 \pm 11.41 \mathrm{~mol}^{-1} \mathrm{~L}$ was obtained. The magnitude of the stability constant is discussed in terms of the relative sizes and the chemical natures of $\beta$-cyclodextrin and imipramine hydrochloride.
\end{abstract}

Keywords: $\beta$-Cyclodextrin, Imipramine hydrochloride, Inclusion complex, Stability constant 


\section{Introduction}

Cyclodextrins were first isolated ${ }^{1}$ as degradation products of starch by Villiers in 1891 and they were characterized as cyclic oligosaccharides by Schardinger ${ }^{2,3}$ in 1904 . It is for this reason that cyclodextrins (cycloamyloses) are described by some authors, especially in the older literature, as Schardinger dextrins. Cyclodextrins can be obtained by enzymatic degradation of $\operatorname{starch}^{2-4}$, a linear polysaccharide consisting of $\alpha-(1 \rightarrow 4)$-linked glucose units per turn (V-amylose $)^{5-7}$. The enzyme cyclodextrin glycosyl transferase, a type of amylase, which is obtained from an organism(bacterium) called Bacillus macerans, can detach a turn from the starch helix and link the two ends of this fragment to give a cyclic molecule. As the enzymes never detach entirely specific lengths, the resulting cyclodextrins contain 6-12 glucose units per ring ${ }^{8}$. A five-membered cyclodextrin is unlikely to be formed due to ring strain $^{9}$, and has not been observed. The main fractions contain $\alpha-, \beta$ - (Figure 1), and $\gamma$ - cyclodextrins with 6,7 , or 8 glucose units respectively; the relative quantities of these three groups depend on the type of enzyme employed and can be influenced by the addition of organic compounds ${ }^{10,11}$. They form inclusion compounds with smaller molecules which fit into their 5-8 $\AA$ cavity.

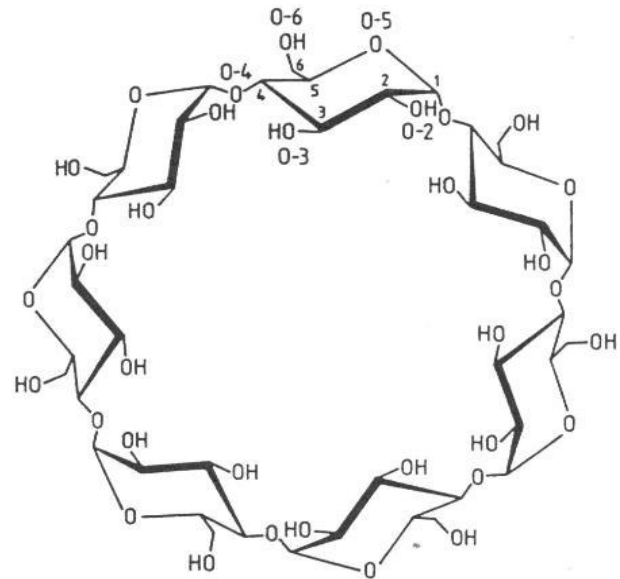

Figure 1. Chemical structure of $\beta$ - cyclodextrin

Cyclodextrin inclusion complexes are of interest for scientific research, because they exist in aqueous solution and can be used to study the hydrophobic interactions which are so important in biological systems. Cyclodextrins can catalyze several chemical reactions and therefore they and their functionalized derivatives (modified cyclodextrins) provide useful enzyme models. Cyclodextrins and modified cyclodextrins can be used advantageously in the production of pharmaceuticals, pesticides, foodstuffs, and toiletry articles - the (microencapsulated) active and aromatic substances enclosed within them are protected from the effects of light and atmosphere and can be easily handled and stored in powder form. Substances which are not very soluble in water become more soluble in the presence of cyclodextrins; creams and emulsions can be stabilized, and the growth and yield of grain harvests can be increased ${ }^{12}$.

The increasing number of publications and patents dealing with inclusion compounds shows that general interest in their physical and chemical properties has grown considerably over 
the past four decades. This is due, on the one hand, to the fact that the study of inclusion compounds furnishes information about non-convalent intermolecular forces and that they also serve as models for studying topochemical problems and the mode of action of enzymes.

The most important property of inclusion compounds is that a "host" component can admit "guest" components into its cavity without any covalent bonds being formed (Figure 2). An inclusion is largely independent of the chemical properties of the guest molecule, the minimum requirement for inclusion complex formation is a size compatibility between host and guest molecules, i.e., guest molecules must fit, entirely or at least partially, into the cyclodextrin cavity. It has also been suggested that forces inherent in the cyclodextrin contribute to association. The water enclosed within the "empty" cyclodextrin cavity could exert such a force; this water is in an unfavourable hydrophobic environment. On expulsion, complex formation is favoured by a gain in entropy as well as by a gain in potential energy ${ }^{13,14}$.

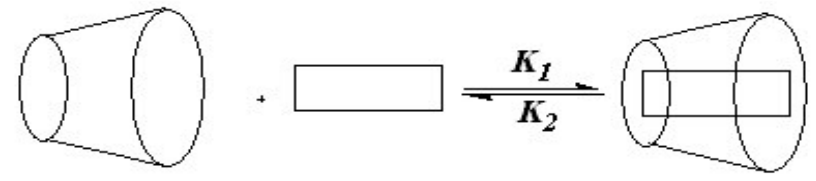

\section{Cyclodextrin Host Guest Inchusion complex}

$$
\text { Inclusion complex association constant }=\mathrm{K}=\frac{[\text { Inclusion complex }]}{[\text { Cyclodextrin host }][\text { Guest }]}
$$

Figure 2. Schematic of inclusion complex formation

Each guest molecule within an inclusion complex is individually surrounded by cyclodextrin and is thus, from the microscopical point of view, encapsulated.

The pharmaceutical modification of poorly soluble drugs by means of inclusion complexation has been extensively studied to improve the dissolution and absorption characteristics of drug molecules. When the fast-dissolving forms of cyclodextrin complexes are administered orally, they must dissociate before absorption, since only the free form of the drug can permeate the lipid barrier of the gastrointestinal (GI) tract. On the other hand, the hydrophilic cyclodextrin and its complex can diffuse across the lipid barrier only with considerable difficulty, if at all. Therefore, the effect of complexation on drug absorption is largely dependent upon the magnitude of the stability constant as well as the dissolution rate of the complex. This overall process can be described by the simplified scheme shown in Figure 3. In this scheme, the rate constant for the dissolution of a solid complex and the stability constant of the complex in the fluids at the absorption site are represented by $K_{d}$ and $K_{c}$, respectively; $K_{a}$ is the rate constant for passage of the free form of the drug across the biomembrane at the absorption site or entry into the circulation and distribution system ${ }^{15}$.

In summary the use of cyclodextrin complexes in industry brings about the following improvements ${ }^{14}$ :

i) Stabilization of light- or oxygen-sensitive substances

ii) Modification of the chemical activity of guest molecules

iii) Fixation of very volatile substances

iv) Modification of the physicochemical properties of guest molecules. 
Gr thact

Btomembrane

Systemte

cinahion

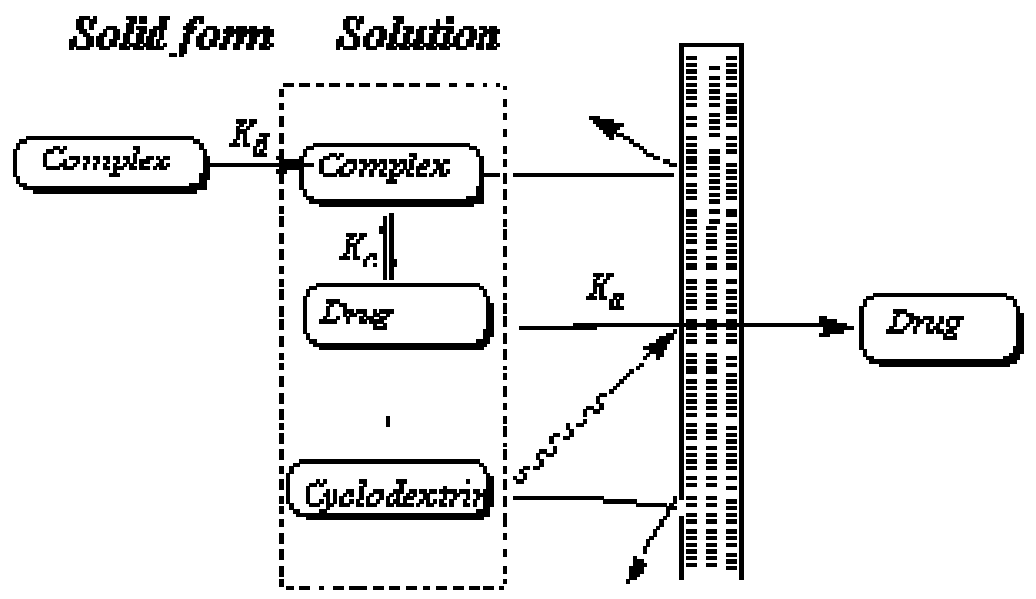

Figure 3. Factors affecting the drug absorption involving cyclodextrin complexation

\section{Experimental}

General

JASCO UV-Visible (model 7850 Japan) was used for the running of the UV-Visible spectra. Metrohm pH meter (Model 620 Switzerland) was used for measuring $\mathrm{pH}$. Chemicals used in this research were purchased from the local agency of the supplier companies : $\beta$ - cyclodextrin (USA), potassium dihydrogen phosphate, sodium dihydrogen phosphate, disodium hydrogen 4phosphate. Deionized water was obtained by using Sibata Pure Still (Model ROD-2, Japan). Buffer solutions with pH 7.4, 7.0 and 6.5 were prepared according to the methods given in literature ${ }^{18}$ and the $\mathrm{pHs}$ were checked and found to be as required.

Preparation of imipramine hydrochloride solution $\left[2.146 \times 10^{-3}\right.$ mol..$\left.^{-1}\right]$

Imipramine hydrochloride $\left(0.034 \mathrm{~g}, 1.073 \times 10^{-4} \mathrm{mmol}\right)$ was dissolved in the desired buffer solution in a $50 \mathrm{~mL}$ volumetric flask and the volume was made up to $50 \mathrm{~mL}$ by adding more of the buffer solution used. This procedure was carried out for each of the three buffer solutions ( $\mathrm{pH} \mathrm{7.4,} \mathrm{7,} \mathrm{6.5).}$

\section{Preparation of $\beta$ - cyclodextrin stock solution}

$\beta$ - Cyclodextrin (0.4494 g, $0.396 \mathrm{mmol})$ was dissolved in the desired buffer solution in a $25 \mathrm{~mL}$ volumetric flask and the volume was made up to $25 \mathrm{~mL}$ by adding more of the buffer solution used. This procedure was carried out for each of the three buffer solutions ( $\mathrm{pH} 7.4$, 7 and 6.5). Generally speaking in these types of research works, the experimental part is consisted of three different steps:

i) Determination of the proper $\mathrm{pH}$

ii) Determination of the maximum absorbance wavelength $\left(\lambda_{\max }\right)$

iii) Determination of the stability constant of the inclusion complex. 


\section{Determination of the proper $\mathrm{pH}: \mathrm{pH} 7.4$}

This is the $\mathrm{pH}$ of the biological fluids. $\beta$ - Cyclodextrin $(0.4494 \mathrm{~g}, 0.396 \mathrm{mmol})$ was dissolved in phosphate buffer solution with $\mathrm{pH} 7.4$ in a $25 \mathrm{~mL}$ volumetric flask and the volume was made up to $25 \mathrm{~mL}$ by adding more of the buffer solution. Then, solutions with different molar concentrations of $\beta$ - cyclodextrin were made up (Table 1) in $5 \mathrm{~mL}$ volumetric flasks. Imipramine hydrochloride $\left(1.67 \mu \mathrm{L}, 2.146 \times 10^{-3} \mathrm{~mol} . \mathrm{L}^{-1}\right)$ was added to each of the $\beta$ - cyclodextrin concentration (Table 1$)$ in a $5 \mathrm{~mL}$ volumetric flasks and the final volume was made up to $5 \mathrm{~mL}$ by adding more of the buffer solution (pH 7.4). The UV - visible spectrum of each of the solutions was taken at wavelength 200 $-350 \mathrm{~nm}$. Each spectrum was taken three times at 30 minutes intervals. Exactly the same amounts were used and the same procedure was carried out for the determinations at $\mathrm{pH} 7.0$ and $\mathrm{pH}$ 6.5.

Table 1. Solutions of the Host - ( $\beta$ - cyclodextrin)

\begin{tabular}{cc}
\hline $\begin{array}{c}\text { Volume of stock solution taken } \\
\text { to make } 5 \mathrm{~mL} \text { final solution, } \mathrm{mL}\end{array}$ & $\begin{array}{c}\text { Molar concentration of diluted } \\
\beta \text {-cyclodextrin, } \mathrm{mol} \cdot \mathrm{L}^{-1}\end{array}$ \\
\hline 0.348 & 0.0011 \\
0.665 & 0.0021 \\
1.013 & 0.0032 \\
1.329 & 0.0042 \\
1.677 & 0.0053 \\
1.994 & 0.0063 \\
2.342 & 0.0074 \\
2.658 & 0.0084 \\
3.006 & 0.0095 \\
3.323 & 0.0105 \\
3.513 & 0.0111 \\
3.829 & 0.0121 \\
4.177 & 0.0132 \\
4.652 & 0.0142 \\
4.747 & 0.0153 \\
\hline
\end{tabular}

\section{Determination of $\lambda_{\max }$}

The measurements were made with $\mathrm{pH} 7.4$ buffer solution. Exactly experiment 6(i) was repeated and the UV-Visible spectra were taken at wavelength $200-350 \mathrm{~nm}$ at $25{ }^{\circ} \mathrm{C}$. From the recorded spectra, it was found that $\lambda_{\max }$ is $250 \mathrm{~nm}$.

\section{Determination of the stability constant $(K)$}

To each of the diluted solutions of $\beta$ - cyclodextrin given in Table 1 in $5 \mathrm{~mL}$ volumetric flasks, imipramine hydrochloride $\left(1.67 \mu \mathrm{L}, 2.146 \times 10^{-3}\right.$ mol. $\left.\mathrm{L}^{-1}\right)$ was added and the volume was made up to $5 \mathrm{~mL}$ by adding more of the buffer solution with $\mathrm{pH}$ 7.4. The flasks were kept at room temperature for 24 hours, then filtered on filter paper. Each time $50 \mu \mathrm{L}$ of the filtrate and $2.95 \mathrm{~mL}$ of the buffer solution with $\mathrm{pH} 7.4$ were placed in a UV-visible cell at $25^{\circ} \mathrm{C}$ and finally the UV-visible spectrum was taken at wavelength $200-350 \mathrm{~nm}$. The absorbance at $\lambda_{\max }=250 \mathrm{~nm}$ of each of the various concentrations of $\beta$ - cyclodextrin added to the imipramine hydrochloride solution was recorded (Table 2) and then plotted versus $\beta$ - cyclodextrin (Figure 4). For each entry of Table 1, the measurements were repeated 3 times. On the basis of $\lambda_{\max }=250 \mathrm{~nm}$ of imipramine hydrochloride and various concentrations of $\beta$ - cyclodextrin, the stability constant was calculated as given in the Results and Discussion section of this article. 


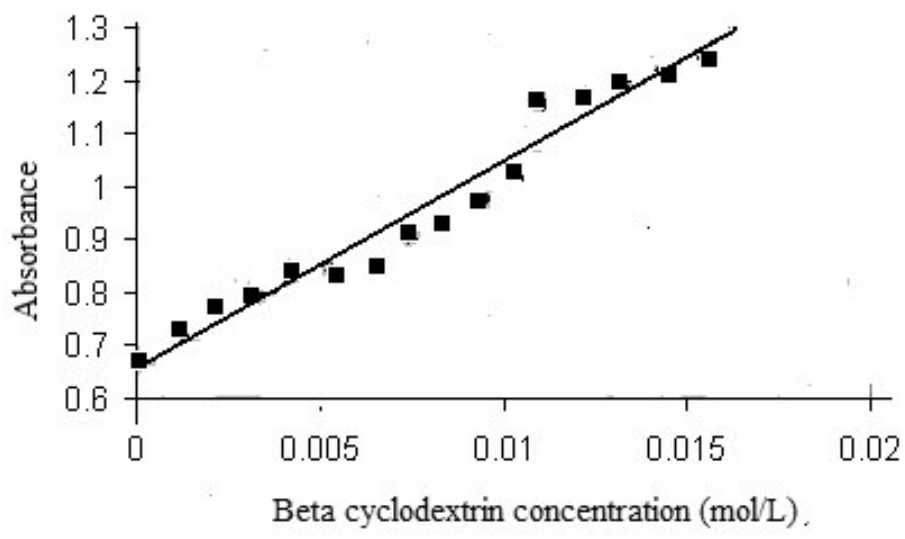

Figure 4. Observed linear absorption diagram of inclusion complexation of beta cyclodextrin and imipramine hydrochloride at $\mathrm{pH} 7.0$ and maximum absorption wavelength $250 \mathrm{~nm}$

\section{Results and Discussion}

Imipramine hydrochloride (Figure 4), (systematic name: 3-(10,11-dihydro-5Hdibenz $[b, f]$ azepin-5-yl)- $N, N$-dimethylpropylamine hydrochloride), which is a white or off-white odourless crystalline powder, is an effective antidepressant. It is a potent inhibitor of noradrenaline reuptake at noradrenergic nerve endings. In this research because of the therapeutically importance of imipramine hydrochloride and its widespread application, it was decided to investigate its interactions with $\beta$-cyclodextrin and also to determine the stability constant of the inclusion complex (K) being formed by using UV-visible spectroscopy. The reasons this technique was used, were due to its simplicity, ease of accessibility and the presence of the aromatic rings in the structure of the guest molecule.

Generally speaking, these investigations must be carried out in several steps. First, the work was carried out at three different $\mathrm{pH}$ values, i.e. 6.5, 7 and 7.4. At each of these pHs, various concentrations of $\beta$ - cyclodextrin (Table 1) was added to a constant amount of imipramine hydrochloride drug and then the UV-visible spectrum was recorded at $200-350 \mathrm{~nm}$ at $25^{\circ} \mathrm{C}$.

The results are given in Table 2. Based on these results, it was concluded that the absorbance for the complex formation was highest in the phosphate buffer solution with $\mathrm{pH}$ 7.4. Therefore, it can be concluded that the proper $\mathrm{pH}$ for the inclusion complex formation between $\beta$ - cyclodextrin and imipramine hydrochloride, as it was found for other guest drugs, was $\mathrm{pH}$ 7.4.

The second task in this research was to find out the optimum $\lambda_{\max }$. Since the best $\mathrm{pH}$ was found to be 7.4 , all the experiments for the determination of $\lambda_{\max }$ were therefore carried out in the buffer solution with $\mathrm{pH}$ 7.4. After addition of various concentrations of $\beta$ cyclodextrin solutions (Table 1) to a constant amount of imipramine hydrochloride, the UV - visible spectra were recorded at $200-350 \mathrm{~nm}$. On the basis of the results obtained, it was concluded that the $\lambda_{\max }$ was $250 \mathrm{~nm}$. 
Table 2. Absorbance of the inclusion complex formed by addition of various concentrations of $\beta$ - cyclodextrin to the imipramine hydrochloride solution with $\mathrm{pH} 7.4$

\begin{tabular}{cc}
\hline $\begin{array}{c}\text { Molar concentration of diluted } \\
\beta \text { - cyclodextrin, mol. } \mathrm{L}^{-1}\end{array}$ & $\begin{array}{c}\text { Observed } \\
\text { average absorbance } \\
(\mathrm{A})\end{array}$ \\
\hline 0.0000 & 0.678 \\
0.0011 & 0.725 \\
0.0021 & 0.766 \\
0.0032 & 0.799 \\
0.0042 & 0.834 \\
0.0053 & 0.841 \\
0.0063 & 0.852 \\
0.0074 & 0.907 \\
0.0084 & 0.923 \\
0.0095 & 0.977 \\
0.0105 & 1.007 \\
0.0111 & 1.155 \\
0.0121 & 1.168 \\
0.0132 & 1.188 \\
0.0142 & 1.211 \\
0.0153 & 1.234
\end{tabular}

Table 3. Calculated stability constant $(\mathrm{K})$ of the inclusion complex between $\beta$-cyclodextrin and imipramine hydrochloride at $\mathrm{pH} 7.4$ and $\lambda_{\max }=250 \mathrm{~nm}$

\begin{tabular}{cc}
\hline $\begin{array}{c}\text { Molar concentration of diluted } \\
\beta \text { - cyclodextrin, mol. } \mathrm{L}^{-1}\end{array}$ & $\begin{array}{c}\text { Calculated } \\
\text { constant }(\mathrm{K}), \mathrm{mol}^{-1} . \mathrm{L}\end{array}$ \\
\hline 0.0011 & 63.30 \\
0.0021 & 62.07 \\
0.0032 & 55.92 \\
0.0042 & 55.00 \\
0.0053 & 45.51 \\
0.0063 & 40.85 \\
0.0074 & 45.79 \\
0.0084 & 43.15 \\
0.0095 & 46.58 \\
0.0105 & 46.37 \\
0.0111 & 63.67 \\
0.0121 & 59.98 \\
0.0132 & 57.22 \\
0.0147 & 55.58 \\
0.0153 & 53.80 \\
\hline
\end{tabular}

The third and the main objective of this research was to determine the stability / association/ thermodynamic constant $(\mathrm{K})$ of the inclusion complex between $\beta$ - cyclodextrin and imipramine hydrochloride at $\lambda_{\max }=250 \mathrm{~nm}$ in phosphate buffer solution with $\mathrm{pH}$ 7.4. As explained in experiment number 8 , the stability constant can be calculated on the basis of the results given in Table 2 and also from the graph in Figure 4. 
The $(\mathrm{K})$ value can be calculated as follows: considered:

In accordance with the Beer-Lambert law, $\mathrm{A}=\varepsilon$.l.c.then the following steps were 1. The initial concentration of imipramine hydrochloride used was $2.146 \times 10^{-3} \mathrm{~mol} \cdot \mathrm{L}^{-1}$, after dilution in the UV-visible cell: [imipramine hydrochloride] $=\mathrm{C}=7.167 \times 10^{-5} \mathrm{~mol} \cdot \mathrm{L}^{-1}$

2. For calculating $\varepsilon$ using Figure 4, when no $\beta$ - cyclodextrin was used, the absorbance could be read to be 0.678 , therefore, $\mathrm{A}=0.678, \mathrm{l}=1 \mathrm{~cm}, \mathrm{c}=$ [ imipramine hydrochloride ] $=7.167 \times 10^{-5} \mathrm{~mol} \cdot \mathrm{L}^{-1}$

$$
\begin{aligned}
& \varepsilon=\frac{0.678}{\left(1 \mathrm{~cm} \times 7.167 \times 10^{-5} \mathrm{~mol} . \mathrm{L}^{-1}\right)} \\
& \varepsilon=9460.025 \mathrm{~mol}^{-1} \cdot \mathrm{cm}^{-1} \cdot \mathrm{L}
\end{aligned}
$$

3. The stability constant can be determined from the following formula:

$$
\mathrm{K}=\frac{\mathrm{A}_{\text {complex }}}{\mathrm{A}_{\text {pure Guest }} \times[\beta-\text { cyclodextrin }]_{\text {Free }}}
$$

From Figure 4, $\mathrm{A}_{\text {complex }}$ for various concentrations of $\beta$ - cyclodextrin can be calculated, e.g., for the third entry of Table 1 we will have,

Therefore,

$$
[\beta \text { - cyclodextrin }]=0.0021 \mathrm{~mol} \cdot \mathrm{L}^{-1} ; \mathrm{A}_{(\text {guest }+\beta-\text { cyclodextrin })}=0.766
$$

$$
\begin{aligned}
& \mathrm{A}_{\text {complex }}=\mathrm{A}_{\text {(guest }+\beta-\text { cyclodextrin) }}-\mathrm{A}_{\text {pure Guest }}=0.766-0.678=0.088 \\
& \mathrm{~A}_{\text {complex }}=0.088
\end{aligned}
$$

4. Now the concentration of the complex can be calculated:

$$
\begin{aligned}
\mathrm{C}_{\text {complex }} & =\frac{0.088}{9460.025 \mathrm{~mol}^{-1} \cdot \mathrm{cm}^{-1} \cdot \mathrm{L} \times 1 \mathrm{~cm}} \\
\text { So, } \quad \mathrm{C}_{\text {complex }} & =9.302 \times 10^{-6} \mathrm{~mol} \cdot \mathrm{L}^{-1}
\end{aligned}
$$

5. $[\beta-\text { cyclodextrin }]_{\text {Free }}=[\beta-\text { cyclodextrin }]_{\text {initial }}-[\beta-\text { cyclodextrin }]_{\text {used }}$

On the other hand: $[\beta-\text { cyclodextrin }]_{\text {used }}=\left[\mathrm{C}_{\text {complex }}\right]$

$$
\begin{aligned}
& {[\beta-\text { cyclodextrin }]_{\text {Free }}=[\beta-\text { cyclodextrin }]_{\text {initial }}-\left[\mathrm{C}_{\text {complex }}\right]} \\
& {[\beta-\text { cyclodextrin }]_{\text {Free }}=0.0021-9.302 \times 10^{-6}=2.091 \times 10^{-3} \mathrm{~mol} \cdot \mathrm{L}^{-1}}
\end{aligned}
$$

6. Now, K can be calculated by substituting the values into the equation given in step 3:

$$
\mathrm{K}=\frac{0.088}{0.678 \times 2.091 \times 10^{-3} \mathrm{~mol} \cdot \mathrm{L}^{-1}}
$$

Therefore, we would have : $\mathrm{K}=62.07 \mathrm{~mol}^{-1} \cdot \mathrm{L}$

Then, $\mathrm{K}$ value for each entry of Table 2 and Figure 4, was calculated in the same way; the results are summarized in Table 3. According to the data give in Table 3, the range of the stability constant is:

$$
\text { Therefore, } \mathrm{K}=\begin{array}{r}
63.67-40.85=22.82 \\
52.26 \pm 11.41 \mathrm{~mol}^{-1} \cdot \mathrm{L}
\end{array}
$$

\section{Conclusions}

On the basis of the relatively small values of the stability constant $(\mathrm{K})$ of the inclusion complex obtained in this research, it can be suggested that under the experimental conditions used in this research and especially the technique UV-Visible spectroscopy used for 
measuring the absorbance, one can quite easily conclude that the interaction between $\beta$ cyclodextrin (the host molecule) and imipramine hydrochloride molecule (the guest molecule) may be very weak. Results obtained by other authors using different techniques; Affinity capillary Electrophoresis ${ }^{16}$ and Ion-Selective Electrodes ${ }^{17}$, indicate a much higher values for the stability constant $\mathrm{K}\left(5423 \pm 189 \mathrm{M}^{-1}\right.$ and $23900 \mathrm{M}^{-1}$, respectively), althought these two results are quite different from each other. However, the small value of the stability constant $(\mathrm{K})$ obtained in this research, can not be due to incompatibility between the cavity size of $\beta$ - cyclodextrin host and imipramine hydrochloride guest molecule and the argument is not plausible, as the results obtained on this complexation by other authors ${ }^{16,17}$ rule out this phenomenon categorically. The only logical and reasonable argument which can be said is the fact that the UV-visible spectroscopy technique is not so accurate and high sensitive enough for this purpose. Therefore, it is suggested that the inclusion complex between imipramine hydrochloride molecule with other modified $\beta$ - cyclodextrins like those having polar and ionic functional groups attached to the $\beta$ - cyclodextrin molecule (at either C-3 or C-6) and also with the linked cyclodextrins be investigated, and finally other more accurate and sensitive techniques such as high performance liquid chromatography (HPLC), HNMR, or CNMR be used for the determination of the stability constant of the inclusion complexation.

\section{References}

1. Villiers A, C. R. Acad. Sci., 1891, 112, 536.

2. Schardinger F, Wien. Klin. Wochenschr., 1904, 17, 207.

3. Schardinger F, Zentralbl. Bakteriol. Parasitenkd. Infektionskr. Hyg. II, 1911, 29, 188.

4. French D, Levine M L, Pazur J H and Norber E, J. Am. Chem. Soc., 1957, 71, 353

5. Winter W T and Sarko A, Biopolymers, 1974, 13, 1447- 1461.

6. Murphy V G, Zaslow B and French A D, Biopolymers, 1975, 14, 1487

7. Matsui Y, Naruse H, Mochida K and Date Y, Bull. Chem. Soc. Jpn., 1970, 43, 1910

8. Pulley A O and French D, Biochem. Biophys. Res. Commun., 1961, 5, 11.

9. Sundarajan P R and Rao V S R, Carbohydr. Res., $1970,13,351$.

10. French D, Adv. Carbohydr. Chem., 1957, 12, 189.

11. Mifune A and Shima A, J. Synth. Org. Chem. Jpn,. 1977, 35, 116.

12. Saenger W, Angew. Chem. Int. Ed. Engl. 1980, 19, 344-362.

13. Van Etten R L, Sebastian J F, Clowes G A and Bender M L, J. Am. Chem. Soc., 1967, 89, 3242.

14. Van Etten R L, Clowes G A, Sebastian J F and Bender M L, J. Am. Chem. Soc., 1967, 89, 3253.

15. Uekama K and Masaki Otagiri, "cyclodextrins in drug carriers systems", CRC Critical Reviews in Therapeutic Drug Carrier Systems, 1987, 3, (1), 1-40.

16. Wei W, Zhang Z J and Ju H X, Chromatographia, 2004, 59, April (No. 7/8).

17. Valsami G N, Koupparis M A and Macheras P E, Pharmaceutical Research, 1992, 9(1)

18. Long C, Ed., "Biochemist's Handbook", Spon, London, 1961. 


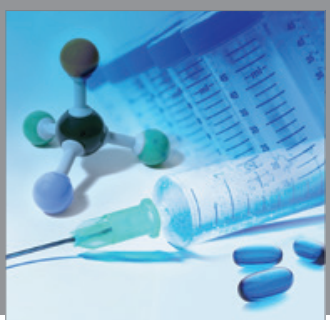

International Journal of

Medicinal Chemistry

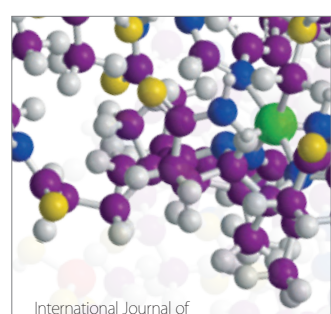

Carbohydrate Chemistry

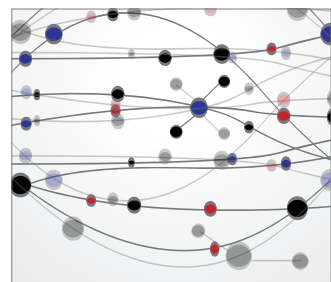

The Scientific World Journal
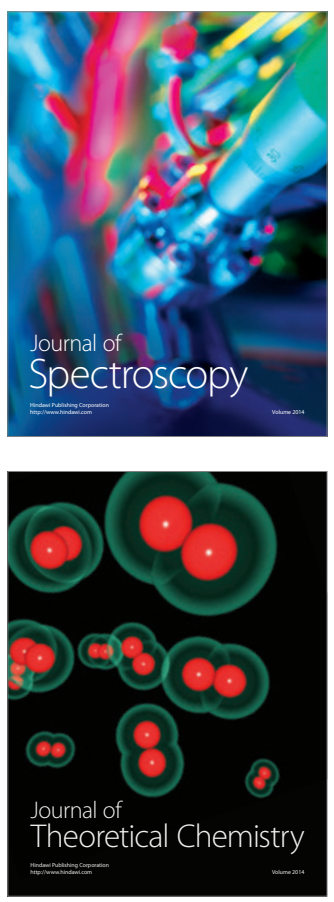
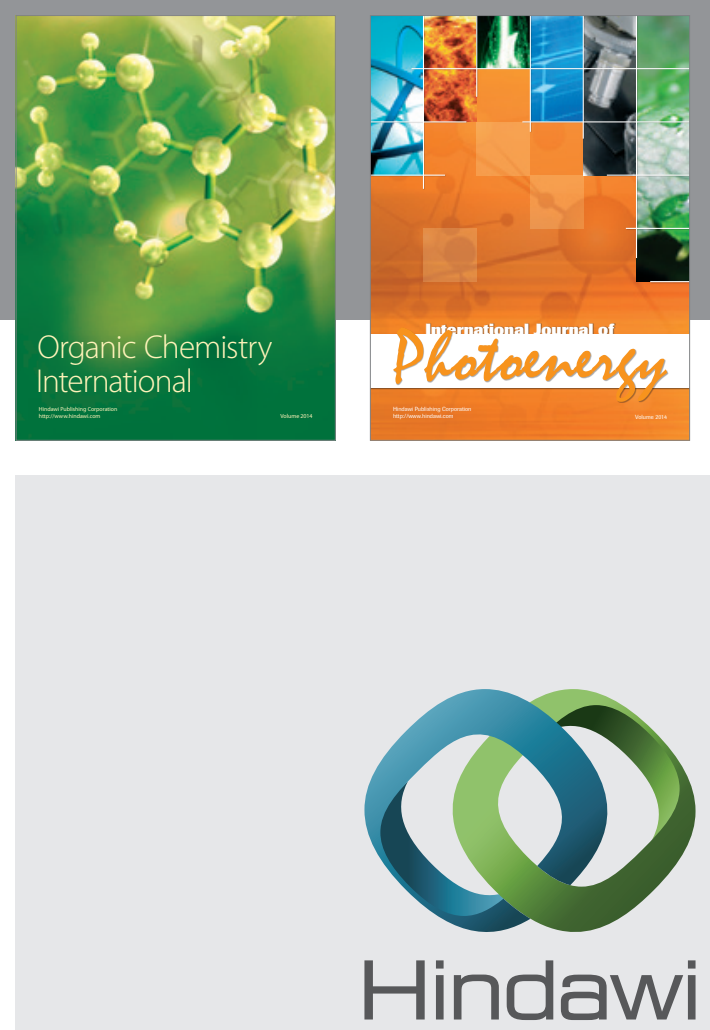

Submit your manuscripts at

http://www.hindawi.com
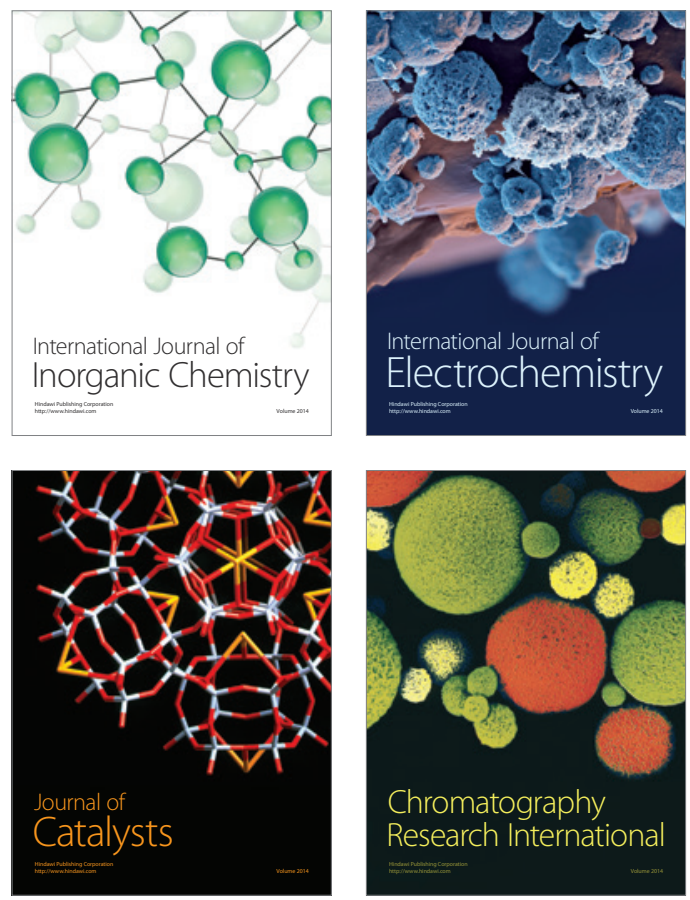
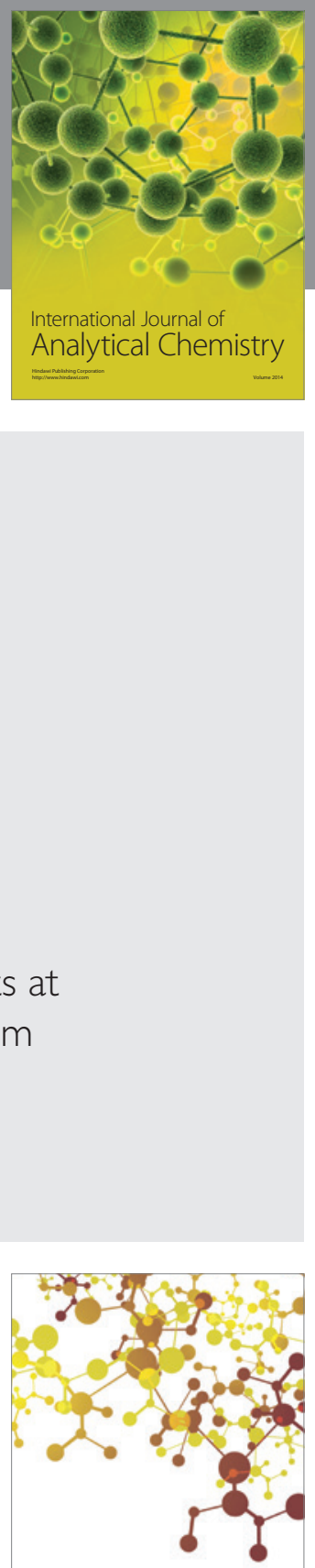

Journal of

Applied Chemistry
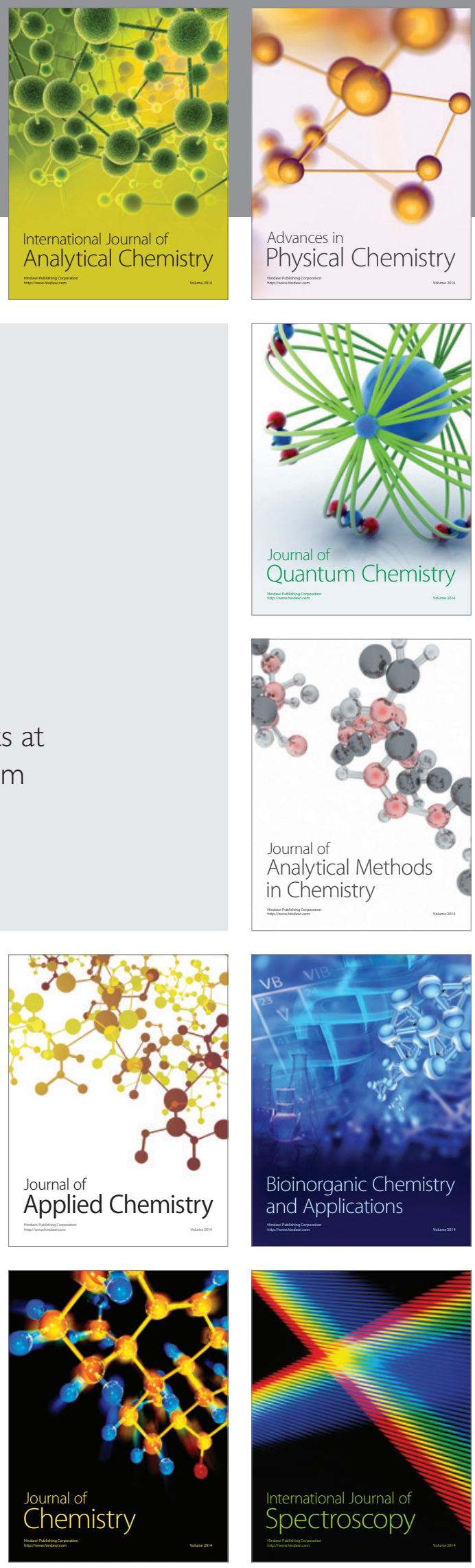